\title{
Study of Hepatitis B Surface Antibody Titres in Female Medical Students Post Vaccination
}

\author{
Rambhala Nagamani*, Anjali Naidu and R. Saraswati Jayanthi \\ Department of Microbiology, Malla Reddy Medical College for Women, \\ Suraram, Hyderabad - 55, India \\ *Corresponding author
}

\section{A B S T R A C T}

\section{Keywords}

Hepatitis B

Vaccine, HB

Surface Antibodies,

Medical Students,

Non Responders.

Article Info

Accepted:

20 January 2017

Available Online:

10 February 2017
Hepatitis B viral infection is a major health problem worldwide. New cases can be prevented by immunization with hepatitis $\mathrm{B}$ vaccine containing the genetically engineered surface antigen. Values of $\geq 10 \mathrm{IU} / \mathrm{ml}$ are considered protective. However a small percentage of individuals fail to develop these levels. Such non responders are at risk of acquiring Hepatitis B virus infection. This is of concern especially in health care personnel. The study comprised of 100 female medical students from Mallareddy Medical College for Women, Suraram who completed the standard 3 dose course of vaccination. Their serum antibody levels were estimated quantitatively by ELISA technique. Information about Their height, weight, associated medical problems was documented. The data was analysed according to body mass index, age, and associated conditions. Though all of them showed protective levels, two of them had levels at borderline, $10 \mathrm{IU} / \mathrm{ml}$. such individuals are considered to be hypo responders $(10-100 \mathrm{IU} / \mathrm{ml})$. Those individuals should be given a booster dose and antibody levels estimated again to assess the efficacy of the booster dose.

\section{Introduction}

Hepatitis B viral infection is a serious liver infection caused by hepatitis B virus (HBV) that can lead to liver failure, cirrhosis or cancer of liver. According to WHO (World Health Organization), about $1 / 3$ of the world's population ( 2 billion) has been infected with $\mathrm{HBV}$, and 400 million people are chronically infected and are at risk of severe disease and death (Lai et al., 2003; Kao et al., 2005). Hepatitis B viral infection is a major health problem in India as there are 40 million estimated carriers (Pankaj Puri, 2014). The virus is transmitted through blood, and body fluids of infected persons, unprotected sex and use of unsterile injections. Health care workers (HCW) are at a greater risk of acquiring Hepatitis B infection due to high frequency of exposure to blood and body fluids and the high contagiousness of HBV (Lai et al., 2003; Kao et al., 2005).

The Hepatitis B viral infection can be controlled by immunization, interrupting routes of transmission, and treating the infected patients (Kao et al., 2005). Vaccination is an easy and cost effective 
measure to prevent disease and infection. Recombinant Hepatitis B vaccine containing surface antigen is safe and effective against Hepatitis B infection.

In addition, vaccination eliminates the incidences of persistent $\mathrm{HBV}$ infection and chronic liver disease and diminishes the pool of chronic carriers, thus limiting transmission of infection to susceptible contacts. Recombinant Hepatitis B vaccine is known as the world's first "anti-cancer vaccine" by world health organization as it is effective in preventing HBV infection and liver cancer (World Health Organization Hepatitis B fact sheet, 2010).

Hepatitis B surface antibody (HBsAb) levels correlate with the immunity to $\mathrm{HBV}$ and levels of anti-HBs antibody are related to the number of doses of vaccine administered (Kubba et al., 2003; Lin et al., 2011).

A complete standard course of vaccination schedule consists of 3 doses (0 month,1month, 6month).Each dose contains $1 \mathrm{ml}$ of recombinant Hepatitis $\mathrm{B}$ vaccine (Gene vac) given deep intramuscularly. A 3 dose course induces protective antibody concentrations in $95 \%$ of healthy infants, children, and adolescents and in $90 \%$ of healthy adults (Assad et al., 1999; Venters et al., 2004).

Vaccine efficacy studies have demonstrated virtually complete protection against acute and chronic hepatitis B in immunocompetent people, with post-immunization anti-HBs levels of $\geq 10 \mathrm{mIU} / \mathrm{mL}$. Therefore, seroprotection against $\mathrm{HBV}$ infection was defined as having an anti-HBs level of $\geq 10$ $\mathrm{mIU} / \mathrm{mL}$ after having received a complete immunization schedule (Elke Leuridan et al., 2011). Duration of protective efficacy can last many years and post vaccination immunological memory remains intact for much longer time (Gilca et al., 2012). Almost
$5-10 \%$ of vaccinees do not respond to these conventional vaccines (non-responders: HBsAbs $<10$ IU/L after 3 doses of conventional vaccine) (Kubbu et al., 2003). Vaccination failure depends on age, obesity, smoking, male gender, and immune suppression (Kwon et al., 2011). The response rates are also lower in immune compromised patients, such as transplant recipients, patients receiving chemotherapy and those with end-stage liver disease. Patients with chronic kidney disease should be vaccinated early in the course of their disease, before the renal disease progresses, to ensure optimal response to vaccination (Perillo et al., 2006).

In non-responders revaccination should be done according to the recommended schedule, therefore there is a need to estimate antibody levels. Approximately 50\% of non-responders develop protective levels after 3 additional doses (MMWR, 2001; 50 No. RR-11).

Post vaccination testing for $\mathrm{HBsAb}$ is indicated for HCWs and should be conducted 1-2 months after the third dose (MMWR. 2011; 60 No. RR-7). HCWs with a reduced immune response to $\mathrm{HBV}$ vaccine in a high disease-prevalent population are at greater risk. Therefore, it is crucial to check postvaccination $\mathrm{HBsAb}$ in all the HCWs. This strategy will ensure safety at work by reducing nosocomial transmission and will have a cost effective impact at an individual as well as a national level, which is very much desired in a resource-limited country (Zeeshan et al., 2007).

There are few studies regarding seroconversion in medical students following vaccination. Many students do not have their antibody levels checked and may be under false impression that they are protected against HBV. The aim of this study is to detect the level of the antibodies against 
HBsAg in the medical students, to identify non responders and suggest revaccination and to analyze the factors responsible for nonresponsiveness.

\section{Materials and Methods}

This is a retrospective study forquantitative estimation of the HBsAbin medical students of $2^{\text {nd }}$ and $3^{\text {rd }}$ year MBBS of Malla Reddy Medical College for Women, Suraram. The participants received $1 \mathrm{ml}$ of recombinant Hepatitis B vaccine (Gene vac) deep intramuscularly at 0, 1, 6 months intervals as prescribed.

The study was approved by the institutional ethics committee. Participants were explained about the study and asked to complete an informed consent form and questionnaire that included questions on health history and data related to $\mathrm{HBV}$ immunization. Their age, height, weight, duration of post vaccination period and any other medical problem is documented. Body mass index (BMI) was calculated from height and weight.

Inclusion criteria: Medical students of $2^{\text {nd }}$ and $3^{\text {rd }}$ year MBBS who had completed the 3 dose standard regimen of hepatitis $B$ vaccine and the time lapse of their last dose of vaccine was more than one month from time of sampling were included in the study.

Exclusion criteria: Students who had not completed the 3 dose standard regimen of hepatitis B vaccine (incompletely vaccinated) or not vaccinated at all were excluded from the study.

Out of the 300 female medical students included, $250(83.3 \%)$ were vaccinated and $50(16.6 \%)$ were partially vaccinated. Of 250 students 102 volunteered to participate in the study during this period. The study was of 2 months duration during August and September 2016.
Sample collection and processing: $3 \mathrm{ml}$ of whole blood is collected from the participants by venipuncture in vacutainer tubes without anticoagulant, and serum is separated. Serum was preserved at 2-4 ${ }^{0} \mathrm{c}$ or frozen when more than 1 week storage is needed. All the samples collected were tested in batches.

Hepatitis B antibody estimation was done quantitatively by ELISA (Enzyme Linked Immunosorbent Assay) using commercial kits (DIAPRO- Sachina Diagnostics) in microbiology laboratory, Malla Reddy Narayana Multi Speciality Hospital to which the medical college is attached. Results were interpreted according to manufacturer's instruction. Data obtained was compiled, compared and analyzed using appropriate statistical methods.

\section{Results and Discussion}

The median age of study subjects was 20 years (range 18-22 years) with 20 years being most common age group (Table 1 ).

Study population includes $74(72.5 \%) 2^{\text {nd }}$ year MBBS students, $28(27.4 \%) 3^{\text {rd }}$ year MBBS students. Time lapse from last dose of vaccine to sample collection ranges from 6 to 15 months. Accordingly subjects were divided into two groups, Group I comprising participants with less than 7 months of post vaccination duration, Group II 8-15 months of post vaccination duration. We found no significant relation between time lapse since the last dose of vaccination ( $p$ value is 0.345).Body mass indices were calculated and participants were grouped into very severely underweight, severely underweight, underweight, normal, overweight, obese class I according to The International classification by WHO 2004 and correlated with the Ab titres (Fig. 1). There was no significant relation between BMI and Ab titres ( $p$ value $0.19)$. In the study sample, there were no non- 
responders (anti-HBs titres $<10 \mathrm{mIU} / \mathrm{ml}$ of blood), $2(2 \%)$ were hypo responders (antiHBs titres $10-100 \mathrm{mIU} / \mathrm{ml}$ of blood) with 10 and $10.37 \mathrm{mIU} / \mathrm{ml}$ respectively and 100 (98\%) were good responders (anti-HBs titres $>100 \mathrm{mIU} / \mathrm{ml}$ of blood) (Table 3).

The overall seroconversion rate (anti-HBs $\geq$ $10 \mathrm{mIU} / \mathrm{mL}$ ) was $100 \%$, there were no nonresponders (anti-HBs titres $<10 \mathrm{mIU} / \mathrm{ml}$ of blood). 100 (98\%) were good responders
(anti-HBs titres $>100 \mathrm{mIU} / \mathrm{ml}$ of blood). 2 (2\%) were hypo responders (anti-HBs titres $10-100 \mathrm{mIU} / \mathrm{ml}$ of blood) with $10 \mathrm{mIU} / \mathrm{ml}$ in Group I and $10.37 \mathrm{mIU} / \mathrm{ml}$ in Group II respectively. Among good responders 3 had titers $>500 \mathrm{mIU} / \mathrm{mL}, 92$ had titers $400-500$ $\mathrm{mIU} / \mathrm{mL}, 8$ had titers $100-400 \mathrm{mIU} / \mathrm{mL}$. Out of 102 participants, 39 had received prior (childhood) vaccination, 20 in group I and 24 in group II (Table 4).

Table.1 Age and number of participants

\begin{tabular}{|l|l|}
\hline Age (yrs) & $\begin{array}{l}\text { No of } \\
\text { participants } \\
\text { (Female) }\end{array}$ \\
\hline $18-20$ & 70 \\
\hline $21-22$ & 32 \\
\hline Total & 102 \\
\hline
\end{tabular}

Table. 2 HBsAb response in two groups of participants

\begin{tabular}{|l|l|l|}
\hline Groups & $\begin{array}{l}\text { No of } \\
\text { Participants } \\
\text { (female) }\end{array}$ & $\begin{array}{l}\text { Mean HBsAb titre } \\
\text { (mIU/ml) }\end{array}$ \\
\hline $\begin{array}{l}\text { I - less than 7 months of } \\
\text { post vaccination period }\end{array}$ & 48 & 417.81 \\
\hline $\begin{array}{l}\text { II - 8-15 months of post } \\
\text { vaccination period }\end{array}$ & 54 & 426.54 \\
\hline
\end{tabular}

Table.3 Distribution of antibody levels in the study group

\begin{tabular}{|l|l|}
\hline Ab titres & No of participants \\
\hline $0-9$ & 0 \\
\hline $10-99$ & 2 \\
\hline $100-399$ & 8 \\
\hline $400-499$ & 89 \\
\hline$\geq 500$ & 3 \\
\hline
\end{tabular}


Table.4 Number of subjects with and without prior (childhood) vaccination and their average antibody titres

\begin{tabular}{|l|l|l|}
\hline Status of vaccination & No & Average Ab titres \\
\hline Prior Vaccination & 44 & 422.61 \\
\hline No Prior Vaccination & 58 & 421.13 \\
\hline
\end{tabular}

Figure.1 Average Ab titres in different subject groups based on the BMI

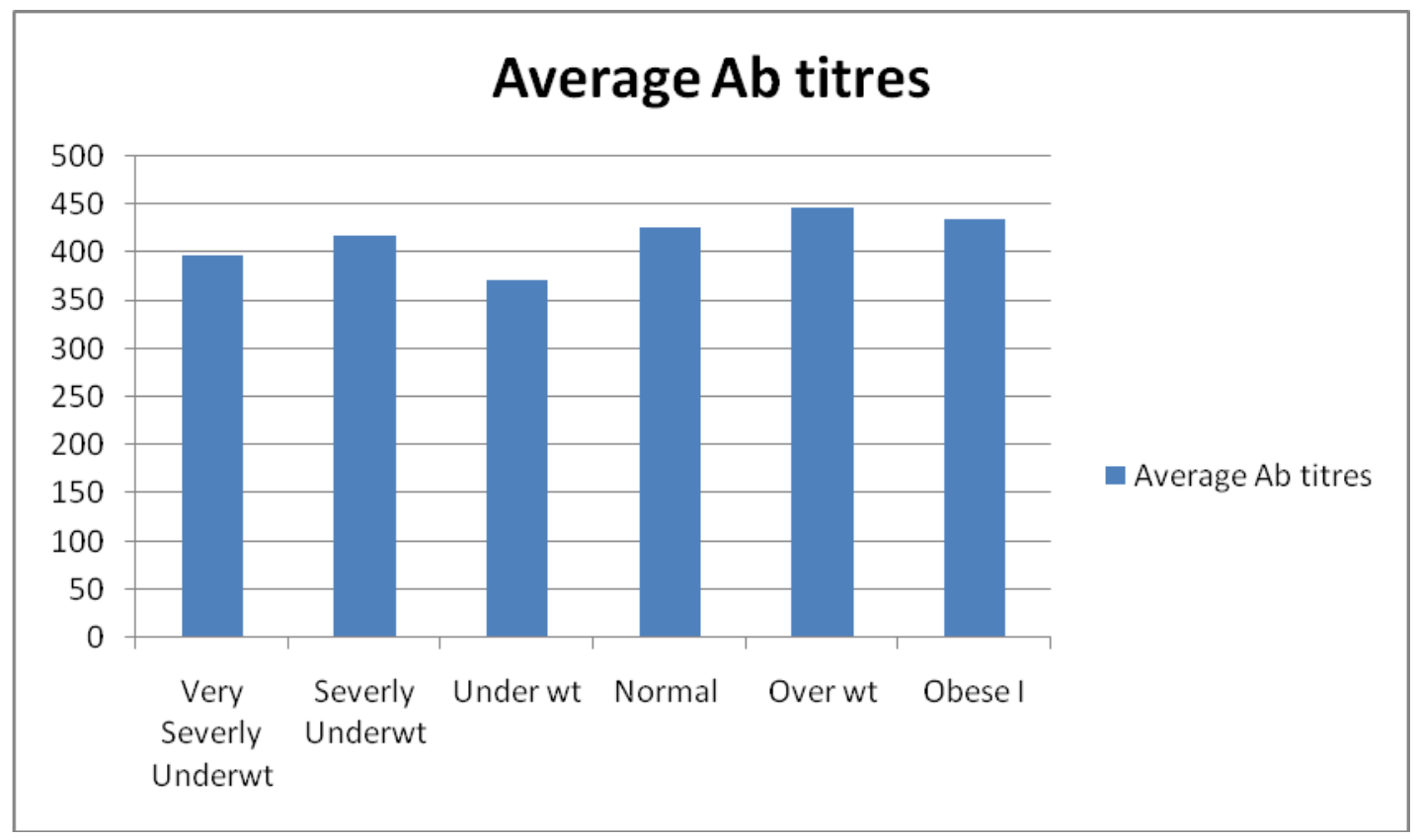

This is a study exclusively on female medical students and highlights the seroconversion rates in this group. In many of the studies from India, health care personnel were assessed for their immune response after hepatitis $\mathrm{B}$ vaccination by estimating the antibody levels and detecting the non responders for further action. One such study by Sunita et al., from Uttarakhand showed that there was $100 \%$ seroconversion by 8 weeks post vaccination with which our study is in concurrence. Another such study is by Bidhan Chakraborthy et al., (2011) from west Bengal. On the other hand, other studies from different parts of the world, like Thomas et al., (2015); Averhoff et al., (1998); Platkov et al., (2001); Zeeshan et al., (2007);
Chathurang et al., (2013) and Sarwat et al., (2014) showed different rates of seroconversion rates, $98.89 \%, 88 \%, 86.5 \%$, $86 \%, 90.1 \%$ and $35 \%$ respectively.

The incidence of non responders was seen more in males in one study by Pavani et al., (2015) $27.1 \%$ vs. $12 \%$ in male vs. females. Thomas et al., (2015) found no statistical significant difference in the rates but found higher levels of antibody titers in females than in males and found association with low Body Mass Index. The same study found the occurrence of hyporesponders in $2(0.43 \%)$ individuals as in our study. They concluded that gender and BMI levels might influence the levels of anti HBs titres (Table 2). 
In present study $50(16.6 \%)$ out of 300 medical students were partially or not vaccinated. This observation suggests that there is a need for adequate vaccine coverage in high risk groups by creating awareness and formulating good vaccination policies.

As part of present study, we have educated our medical students regarding the importance of screening for anti-HBs titers to decrease the risk of $\mathrm{HBV}$ infection and also identified the medical students that had not been vaccinated previously despite being at a high risk of contracting the infection.

In conclusion, the present study that in all medical colleges, students should be encouraged to take $\mathrm{HB}$ vaccination and active follow-ups should be done, with reminders to track completion of the vaccine series. Postvaccination estimation of titers should be made mandatory in all healthcare institutions to assess the protection attained through the vaccine. Those who do not achieve the protective anti-HBsAb titres for the intial 3 dose vaccine regime should be either given a booster dose or repeat 3 dose vaccine regimens depending on their $\mathrm{Ab}$ titres and follow-ups should be done for estimation of $\mathrm{Ab}$ titres.

\section{References}

Assad, S., Francis, A. 1999. Over a decade of experience with a yeast recombinant hepatitis B vaccine. Vaccine, 18: 57-67.

Baddavithana, A.K., F. Noordeen, C.M. Mendis, A.M.S.B. Abeykoon. 2015. Sri Lankan, J. Inf. Dis., vol. 5(1): 7-12

Averhoff, F., Mahoney, F., Coleman, P., Schatz, G., Hurwitz, E., Margolis, H. 1998. Immunogenicity of Hepatitis B Vaccines. Implications for persons at occupational risk of hepatitis B virus infection. Am. J. Prev. Med., 15(1): 1-8.
Bidhan Chakraborty, Tanvir Bashar, Konok Roy, Rashed Noor, and M. Majibur Rahman. 2011. Persistence of Anti-HBs Antibody and Immunological Memory in Healthy Individuals Vaccinated With Hepatitis B Vaccine Stamford, $J$. Microbiol., Vol. 1, Issue 1 ISSN: 20745356.

Lin, C.C., C.Y. Yang, C.T. Shih, B.H. Chen, and Y.L. Huang. 2011. "Waning immunity and booster responses in nursing and medical technology students who had received plasma-derived or recombinant hepatitis B vaccine during infancy," The American J. Infect., vol.39, no.5, pp.408-414.

Elke Leuridan and Pierre Van Damme. 2011. Hepatitis B and the Need for a Booster Dose, Clin. Infect. Dis., 53(1): 68-75.

Gilca, V., et al., 2012. Antibody persistence and the effect of a booster dose given 5, 10 or 15 years after vaccination with a recombinant hepatitis $\mathrm{B}$ vaccine. 52nd Inter science Conference on Antimicrobial Agents and Chemotherapy, San Francisco, abstract G-1047.

Immunization of health-care personnel: recommendations of the Advisory Committee on Immunization Practices [ACIP]. MMWR 2011;60 [No. RR-7]).

Kao, J.H., Chenn, D.S. 2005. Hepatitis B vaccination: to boost or not to boost? Lancet, 366: 1337-1338

Kubba, A.K., Taylor, P., Graneek, B., Strobel, S. 2003. Non-responders to hepatitis B vaccination: A review. Commun. Dis. Public Health, 6: 106-12.

Kwon, S.Y., Lee, C.H. 2011. Epidemiology and prevention of hepatitis B virus infection. Korean J. Hepatol., 17(2): 8795.

Lai, C.L., Ratziu, V., Yuen, M.F., Poynard, T. 2003. Viral hepatitis B. Lancet, 362: 2089-2094. 
Chathuranga, L.S., F. Noordeen, A.M.S.B. Abeykoon. 2013. Immune response to hepatitis B vaccine in a group of health care workers in Sri Lanka, Int. J. Infect. Dis.

Pankaj Puri. 2014. Tackling the Hepatitis B disease burden in India. J. Clin. Exp. Hepatol., 4(4): 312-319.

Pavani, K., Srinivas Rao, M.S., et al., 2015. immune response to hepatitis $b$ vaccine in health care workers in tertiary care hospital in south india Indian $J$. Microbiol. Res., 2(4): 210-213.

Perrillo, R., Nair, S. 2006. Hepatitis B and D. Chapter 75, pages: 1666-9: Feldman M, Friedman L S, Brandt LJ.(Eds): Sleisenger and Fordtran's Gastrointestinal and liver disease Pathophysiology / Diagnosis/ Management 8th Edition 2006 Saunders Elsevier Inc.

Platkov, E., Shlyakhov, E., Glick, V., Khalemsky, S., Fischbein, A. 2001. Humoral immune response of hospital employees Induced by a recombinant Hepatitis B vaccine: 5 years after the primary standard immunization. The $J$. Preventive Med., 9(3): 59-66.

Thomas, R.J., et al., 2015. Prevalence of nonresponsiveness to an indigenous recombinant hepatitis B vaccine: A study among South Indian health care workers in a tertiary hospital, J. Med. Microbiol., 33, Suppl S1:32-6

Saberifiroozi, M., Gholamzadeh, S., Serati, A.R. 2006. The long-term immunity among health care workers vaccinated against hepatitis $\mathrm{B}$ virus in a large referral hospital in southern Iran. Arch. Iran. Med., 9(3): 204-7.

Sarwat, F., Ajaz, H. and Ayesha, A. 2014. Hepatitis B vaccination status of health care workers and their antiHBs titres - A cross sectional study. Al Ameen J. Med. Sci., 7(3): 217-223.

Sunita Tripathy., H.C. Sati, et al., 2011. study of immune response after hepatitis b vaccination in medical students and health care workers ISSN- 0301-1216 Indian J. Prev. Med., vol.42 no.3.

The international classification of adult underweight, overweight and obesity according to BMI Adapted from WHO, 1995, WHO, 2000 and WHO 2004.

Updated US Public Health Service guidelines for the management of occupational exposures to $\mathrm{HBV}, \mathrm{HCV}, \mathrm{HIV}$ and recommendations for post exposure prophylaxis, $M M W R$, 50: No. RR-11.

Venters, C., Graham, W., Cassidy, W. 2004. Recombivax-HB: perspectives past, present and future. Expert Rev. vaccines, 3: 119-129.

World Health Organization. 2008. Hepatitis B World Health Organization factsheets 2008. Geneva, World Health Organization, 2010.

Zeeshan, M., Jabeen, K., Ali, A.N., et al., 2007. Evaluation of immune response to Hepatitis B vaccine in health care workers at a tertiary care hospital in Pakistan: an observational prospective study. BMC Infect. Dis., 7: 120.

\section{How to cite this article:}

Rambhala Nagamani, Anjali Naidu and Saraswati Jayanthi, R. 2017. Study of Hepatitis B Surface Antibodytitres In Female Medical Students Post Vaccination. Int.J.Curr.Microbiol.App.Sci. 6(2): 1053-1059. doi: http://dx.doi.org/10.20546/ijcmas.2017.602.118 